\title{
Vowel Length in Nuer
}

\author{
Irina Monich \\ University of Surrey
}

\section{Introduction}

Three-way vowel length contrasts are extremely rare cross-linguistically but are known to exist in some Western Nilotic languages (Remijsen \& Gilley 2008). The status of Nuer in relation to this phenomenon has been somewhat controversial. Although a three-way length contrast has been reported for the languages most closely related to it (Dinka and Reel; for the latter, see Reid 2010), it has not generally been observed in Nuer (Crazzolara 1933, Faust and Grossman, forthcoming), nor is it reflected in the orthography currently in use; Vandevort (n.d.) alludes to it but only intermittently represents it. Based on newly collected data we confirm that Nuer does indeed display three degrees of length, although this was either not reported or explicitly rejected in previous accounts. We focus here on nominal inflection, as it represents a particularly complex aspect of Western Nilotic morphology.

Nuer is a Western Nilotic language of the Nilo-Saharan language family with almost 900,000 speakers worldwide ${ }^{1}$. Nuer morphology, especially its nominal system, is notoriously complex, appearing to be exceedingly chaotic and lacking in predictability (Frank 1999, Baerman 2012). Table 1 shows a small sample of possible patterns. (All examples in this paper come from our own fieldwork.)

Table 1. A sample set of nominal paradigms

\begin{tabular}{|c|c|c|c|c|c|}
\hline NOM SG & GEN SG & LOC SG & NOM PL & GEN/LOC PL & Gloss \\
\hline duọ:::p & duọ:f & dụf & duọ́:f & duọ́:f-nì & 'road' \\
\hline ciên & ciên & cíẹn & ciê::n & ciên-nì & 'back' \\
\hline tuô::y & tuôy/tòy-র̂́ & tuôy/tòy-র̂́ & tuôy & tuôy-nì & 'egg' \\
\hline dí:t & dîع::t & dîع::t & dî::t & dî::t-nì & 'bird' \\
\hline$b \hat{\varepsilon}:: r$ & bêar & bêar & bêar-ì & b̂ैar-ì & 'flag' \\
\hline
\end{tabular}

Although Nuer nominal system makes some use of suffixation, most of the morphological work is done by modification of the stem along the following four parameters: quality and quantity of the stem vowel, tone and, in some Western dialects, articulation of the stem-final consonant. This article focuses on vowel length exclusively. It aims to show that there are indeed three degrees of vowel length in Nuer but that they do not have equal status. While the current analysis is a work in progress, subject to future modifications, we would like to nevertheless suggest a path towards a plausible view of the Nuer nominal system and particularly of the place that vowel length alternations have in it.

\footnotetext{
* The research presented in this article is funded by the Arts \& Humanities Research Council (UK) under grant AH/L011824/1 ('Morphological Complexity in Nuer'). We would also like to thank our Nuer consultants John Nguany Gai Yok, Andrew Kuong, Yak Wichok, Chuol Tut, Mathew Juany Riek, John Chuol Kuek, Lam Muang, Phillip Muk, Joseph Gatkuoth, John Makuac, John Pelpel for sharing their knowledge with us. This paper has been previously presented as a poster at the meeting of North-East Linguistic Society on October 15, 2016.

${ }^{1}$ Ethnologue https://www.ethnologue.com/language/nus
} 


\section{Basics of Nuer phonology}

The consonant inventory of Nuer is shown in Table 2. There is no phonemic contrast between voiceless stops and fricatives in the word-initial position, and no contrast between voiced and voiceless stops in noninitial positions. The consonants in parentheses exist as independent phonemes in some dialects of Western Nuer, being contrastive with stops in non-initial positions.

Table 2. Consonant phonemes

\begin{tabular}{|l|l|l|l|l|l|}
\hline & Labial & Dental & Alveolar & Palatal & Velar \\
\hline Voiced stop & $\mathrm{b}$ & $\mathrm{d}$ & $\mathrm{d}$ & $\mathrm{J}$ & $\mathrm{g}$ \\
\hline Voiceless stop & $\mathrm{p}$ & $\mathrm{t}$ & $\mathrm{t}$ & $\mathrm{c}$ & $\mathrm{k}$ \\
\hline Fricative & $(\mathrm{f})$ & $(\theta)$ & $(\mathrm{r})$ & $(\mathrm{c})$ & $(\mathrm{h})$ \\
\hline Nasal & $\mathrm{m}$ & $\mathrm{n}$ & $\mathrm{n}$ & $\mathrm{n}$ & $\mathrm{g}$ \\
\hline Lateral & & & $\mathrm{l}$ & & \\
\hline Trill & & & $\mathrm{r}$ & & \\
\hline Glides & $\mathrm{w}$ & & & $\mathrm{j}$ & $\mathrm{J}$ \\
\hline
\end{tabular}

We found 15 vowel phonemes, illustrated in Figure 1. All vowels except for $/ \mathrm{N} /$ come as a modal/breathy pair (breathiness is indicated by two dots underneath a vowel). There are therefore 4 high, 4 close mid, 4 open mid, one central and 2 low vowels.

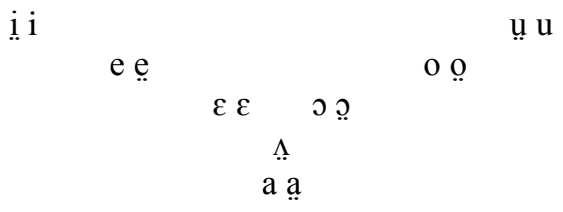

Fig. 1 Nuer vowel inventory

In addition, in the course of various morphological operations high and open mid vowels in Fig. 1 undergo

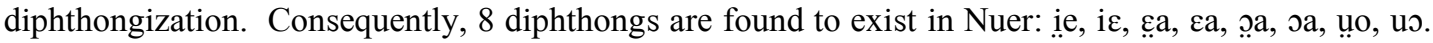

Nuer is a tonal language. There are two lexically specified tones: H, L. An intriguing feature of the Nuer tonal system is that the H-tone over modal vowels is always realized as a fall.

\section{Vowel length in Nuer: data and analysis}

Vowels - both diphthongs and monothongs - occur in three degrees of length: short, long and overlong. The approximate durations of the Nuer vowels are provided in Table 3.

Table 3. Approximate durations of Nuer vowels

\begin{tabular}{|l|l|l|}
\hline Short & Long & Overlong \\
\hline$\approx 90 \mathrm{~ms}$ & $\approx 120 \mathrm{~ms}$ & $\approx 200 \mathrm{~ms}$ \\
\hline cak'tick.SG.NOM' & $c a: k^{\prime}$ 'milk.PL.NOM' & $c a:: k^{\prime}$ milk.PL.GEN' \\
\hline
\end{tabular}

The overlength is very easy to perceive. The greatest empirical challenge in regards to the transcription of Nuer vowels is posed by the difference between short and long vowels. As Table 3 shows, short and long vowels are very close in duration and are quite hard to distinguish. However, existence of minimal pairs such as $c a k$ 'tick.SG.NOM' $\sim c a: k$ 'milk.PL.NOM' above or $l \varepsilon k$ 'pestle' $\sim l \varepsilon: k$ 'k.o. fish' convinced us that these two vowel lengths are indeed contrastive. 
The problem of differentiating between long and short vowels is compounded by the limitations of the Nuer orthography which distinguishes only two degrees of vowel length. The informally accepted orthography which has been primarily employed in the translation of the Bible, uses a single grapheme for short and long monothongs and a double grapheme for overlong monothongs (i.e. 'a' vs 'aa'). Our Nuer consultants had difficulty in pinpointing the property which, in their mind, distinguishes cak from $c a: k$ and l $\varepsilon k$ from $l \varepsilon: k$. In contrast, they were all quite aware that the vowel of ca::k and of le::k is longer than the vowels in those other items. When asked what distinguishes items such as $c a k$ from $c a: k$, a few felt that there was a length difference and suggested that $c a: k$ should be written with two vocalic graphemes (a Nuer convention for indicating vowel length). However, these consultants then reneged on that suggestion when faced with the problem of how to write the word $c a:: k$ 'milk.PL.GEN'. Though thrown off by the lack of orthographic means to capture the three degrees of vowel length, they nevertheless correctly identified the items with a long vowel as opposed to the short vowel. One consultant, who had some music education, went as far as describe the difference between $c a k, c a: k$ and $c a: k$ as that between an eighth, a dotted eighth and a half note. It nevertheless, remains a challenge for us to determine whether a particular item contains a long or a short vowel in the absence of a relevant minimal pair, especially that vowel length is so susceptible to variation depending on the individual rate of speech.

However, although a triple vowel length contrast is evident at the phonological level, from a morphophonological point of view they do not all have equal status. Let us first consider the distribution of the various vowel lengths in the nominal paradigm.

Nuer noun has three cases: Nominative, Genitive and Locative. Genitive and Locative are always syncretic in the plural (i.e. a single Plural Oblique form) and are almost always produced by suffixation of the Nom Pl form with -ni. In the majority of cases, Genitive and Locative are also syncretic in the singular. Therefore, the three forms that determine most nominal paradigms are Nom Sg, Nom Pl and Gen Sg, and our subsequent discussion will focus on these.

Outside of the employment of the plural suffix $-n i$ and the singular oblique suffix $-(k)_{n}$, all inflection is done by means of modification of the vowel quality (lowering/removal of breathiness or raising/addition of breathiness), quantity, tone and, in some Western dialects, the mutation of the stem-final consonant. These properties are modified in the individual paradigms in seemingly unpredictable manner, yielding dozens of permutations. At this point in our analysis we believe that the best way to capture the system is by organizing the nouns into independent classes which correspond to individual properties that are being modified, i.e. length classes, vowel quality classes, tonal classes, etc. This way, we can capture individual patterns that we observe in Nuer nominal inflection without making reference to other phonological properties that are undergoing simultaneous modification. What creates the apparent richness and unpredictability of nominal inflection in Nuer, is the fact that the classes relating to individual phonological properties overlap, yielding dozens of combinations.

The table below shows the attested patterns of vowel length alternation for the three forms under consideration. Note that suffixation in the Gen Sg precludes length alternations (length is the same as in the Nom $\mathrm{Sg}$ ), so it does not feature in these paradigms. 
Table 5. Nuer Length Classes

$\mathrm{V}=$ short stem vowel, $\mathrm{VV}=$ long stem vowel, $\mathrm{VVV}=$ overlong stem vowel, $\mathrm{S}=$ suffixed plural form

\begin{tabular}{|c|c|c|c|c|c|c|c|}
\hline \multirow[t]{2}{*}{ Class } & \multirow[t]{2}{*}{ Nom Sg } & \multirow{2}{*}{$\begin{array}{l}\text { Gen } \\
\text { Sg }\end{array}$} & \multirow{2}{*}{$\begin{array}{l}\text { Nom } \\
\text { PI }\end{array}$} & \multicolumn{4}{|l|}{ Examples } \\
\hline & & & & gloss & Nom Sg & Gen Sg & Nom Pl \\
\hline \multicolumn{8}{|c|}{ Unsuffixed plurals } \\
\hline I & $\mathrm{V}$ & V & $\mathrm{V}$ & 'buffalo' & mếk & mèk & mêk \\
\hline II $\mathbf{a}$ & $\mathrm{V}$ & VVV & VVV & 'Nile perch' & cíl & cá::1 & ch́::1 \\
\hline b & $\mathrm{VV}$ & VVV & VVV & 'bird' & dî:t & dì $\varepsilon: t$ & dî::t \\
\hline III a & $\mathrm{V}$ & VVV & $\mathrm{V}$ & 'bead' & tîk & tîع::k & tîعk \\
\hline b & VV & VVV & VV & 'heart' & lò:c & lôa::j & lô:ç \\
\hline IV & $\mathrm{V}$ & $\mathrm{V}$ & VVV & 'rat' & kùn & kúon & kúo::n \\
\hline $\mathbf{V}$ & VVV & $\mathrm{V}$ & $\mathrm{V}$ & 'elephant' & gwó::r & gwóar & gwór \\
\hline \multicolumn{8}{|c|}{ Suffixed plurals } \\
\hline VI & VVV & $\mathrm{V}$ & $\mathrm{S}$ & 'pitcher' & lîع::r & lîعr & lée::r-ì \\
\hline VII & $\mathrm{V}$ & $\mathrm{V}$ & $S$ & 'spear' & mút & múot & mùtní \\
\hline VIII & $\mathrm{V}$ & VVV & $\mathrm{S}$ & 'chair' & kôm & k̇̈a::m & k’̀a::m-ní \\
\hline
\end{tabular}

The paradigms above are of two types. Either there is no length alternation, and the vowel is short throughout, or there is a length alternation between short and overlong or long and overlong. The short vs long distinction is found only in Nom Sg and Nom Pl, but not in the Genitive case.

Even though plurality is usually expressed by ablaut-like changes to the stem - modification of vowel quality and quantity - some plurals are formed by means of suffixation in addition to modification of the stem properties.

Let us first consider length classes with unsuffixed plurals. As a rule, the Nom Pl has the vowel longer or of the same length as the vowel of Nom Sg. However, there is one nominal class (length class V) where the reverse is true, and the Nom Sg has a longer vowel than the Nom Pl. This class consists of the so-called "basic plurals" (Storch 2005, Dimmendaal 2000) where the default number form is the plural, while the singular is the marked form. This class consists of items that are most often conceived of in plurality or pairs, such as animals that live in groups (ostrich, elephant, fish), body parts (leg, hip, elbow, intestine), or small objects that occur in great quantities (grain, pebble, star).

The suffixed plurals are produced by suffixation of $-n i$ to the stem. The stem can be modified in any way that the unsuffixed plural stem might be, i.e. the vowel maybe lowered, raised, or lengthened. At first glance therefore it appears that the suffixed plurals classes correspond to the unsuffixed plural classes and differ from them only in having a suffix attached to the plural form. However, there is a slight complication to this generalization. The class with an overlong vowel in the Nom Sg (i.e. length class VI) differs from the "basic plural" class in some subtle but significant ways. First of all, it does not contain nouns which fit in with the "basic plurals" semantically: "door", "pitcher", "flag", "night" are all items that are unlikely to be conceived of in plurality. Also, some of the plurals in this class contain an overlong vowel in the suffixed plural, making the notion that this class is just the "basic plural" class with a suffix -ni added on, unlikely. These considerations convince us to list the suffixed classes separately from the unsuffixed classes.

A crucial observation here is that although there are three phonemic length distinctions, there are no three-way length alternations, which leads us to propose that lexical items are specified for just two degrees of length: short and long. Overlong vowels are always a product of morphological operations. Therefore, all inflectional operations involve lengthening by up to two degrees: $\mathrm{V}^{\mathrm{n}} \rightarrow \mathrm{V}^{3}$, while the shortest stem vowel in a given paradigm shows the underlying length of the stem. The lengthening can take place in the Gen $\mathrm{Sg}$, Nom Pl, or both, or it may take place in the Nom Sg (as in "basic plural" classes). The lengthening also may fail to take place anywhere in the paradigm.

Evidence for this approach, i.e. positing lengthening as opposed to shortening, comes from some dialects of Western Nuer, where stem-final palatal and velar consonants are lenited under certain conditions: $\mathrm{k} \rightarrow \mathrm{\gamma}$, $\mathrm{c} \rightarrow \mathrm{j}$. The voiced palatal and velar continuants appear after all overlong vowels and also after long vowels 
if there are short stem vowels present elsewhere in the paradigm. The velar and palatal stops appear after all short vowels and also after long vowels if there are no short stem vowels in the paradigm. This distribution of lenited consonants is illustrated in Table 6.

Table 6. Western Nuer consonantal lenition

\begin{tabular}{|c|c|c|c|c|c|c|c|c|}
\hline \multirow[b]{2}{*}{ nom sg } & \multicolumn{2}{|c|}{ 'k.o.fish' } & \multicolumn{2}{|c|}{ 'shoelace' } & \multicolumn{2}{|c|}{ 'right hand' } & \multicolumn{2}{|l|}{ 'fire' } \\
\hline & lêck & long & lạ̀::y & overlong & cwéc & short & mà:c & long \\
\hline gen sg & lèa::y & overlong & là::y & overlong & cwê::j & overlong & mâ::j & overlong \\
\hline nom pl & lê::y & overlong & lạ̀:k & long & cwêç & short & mại::j & overlong \\
\hline
\end{tabular}

The distribution of lenited consonants can be accounted for if we assume that the lenition is associated with lengthening of the stem vowel. Crucially, overlong stem vowels in Nom Sg forms of Class VI are followed by lenited consonants, for example, thị:::y 'door' or thị ::y 'bull'. The consonantal lenition in these items suggests that this class of nouns is characterized by lengthening in the Nom Sg, similarly to the "basic plural" class. It is noteworthy, perhaps, that with "basic plural" nouns we also find consonantal lenition in the Nom Sg in the relevant dialects: $r e::$ "fish.SG.NOM" vs $r \varepsilon c$ "fish.PL.NOM". Interestingly, for some speakers the lengthened Nom Sg forms of length class V have optional variants such as thị: $k$ and thị $k$ which contain a shorter vowel followed by an unlenited final consonant. It is therefore possible that for these speakers lengthening in the Nom Sg of this class is optional.

Diachronically, the origin of superlength seems to be relatively clear, at least as far as the nominative singular plural alternation is concerned. The ancestral language had two degrees of vowel length and suffixal morphology. At some point, the old suffixes were lost in Western Nilotic languages, such as Nuer (on the comparable situation in Dinka, see Andersen 1990). Due to compensatory lengthening triggered by the loss of old suffixes in Nuer, short and long vowels lengthened to "overlong", a newly developed degree of length. More conservative Burun languages such as Mayak, still preserve the suffixal morphology lost in Nuer. Table 7 below shows two nouns: the noun 'dog' with a long vowel in the unmarked singular form and a suffix in the plural, and the noun 'tooth' with a short vowel in the unmarked plural form and a suffix in the singular form ${ }^{2}$. The Nuer cognates show that, while the two nouns are lexically specified to have contrastive vowel length in the unmarked forms - short in 'tooth' and long in 'dog' - in the marked forms the presence of the suffixes translated to the overlength of the stem vowel.

Table 7. Mayak-Nuer comparison ${ }^{3}$

\begin{tabular}{|l|l|l|l|}
\hline Gloss & Form & Mayak & Nuer \\
\hline 'dog' & singular & go:k & jọ :k \\
\hline & plural (marked) & guy-in & jọ́:: \\
\hline 'tooth' & singular (marked) & ley-it & lẹ̣:: \\
\hline & plural & lek & lèc \\
\hline
\end{tabular}

By analogy, we can suppose that overlength in the genitive singular was due some prior suffix, though we have no direct evidence for what that might have been, as the genitive case as such is unique to Nuer and Reel (which has a comparable pattern). On the other hand the pattern of overlong vowel in the nominative

${ }^{2}$ Note that suffixation in Mayak regularly induces shortening of the stem vowel. We are assuming that this did not happen in the system ancestral to that of Nuer.

${ }^{3}$ The Mayak data comes from Andersen (1999). 
singular versus short vowel in the genitive singular remains something of a mystery. On the reconstruction offered here, that would suggest a prior state with an overt suffix in the nominative singular versus no suffix in the genitive singular - certainly possible, but something for which we have no evidence.

Overlength is not the only phonological property that emerges exclusively as a result of morphological operations in Nuer. The vowels /e, $o$, a/ never occur as part of a lexical specification but always emerge as a result of morphological processes, as modified counterparts of vowels $/ \varepsilon / \mathrm{e} /, / \mathrm{o} / \mathrm{o} / \mathrm{and} / \mathrm{a} / \mathrm{N} /$. Likewise, in some Western Nuer dialects, consonants $/ \mathrm{f} / \mathrm{/} / \mathrm{r} /$, and $/ \mathrm{h} /$, emerge in the course of inflectional stem modification, as variants of consonants $/ \mathrm{p} /, / \mathrm{t} /$, and $/ \mathrm{k} /$. This consonantal mutation is morphologically, not phonologically, conditioned and is a phenomenon separate from the lengthening-triggered lenition which was discussed earlier in this article.

\section{Conclusion}

Based on the results of our fieldwork, we conclude that there are three degrees of vowel length in Nuer. However, we believe that lexical items in Nuer are specified for two degrees of vowel length only: long and short. The third degree of vowel length (overlong) has a solely inflectional function. Therefore, the three degrees of vowel length do not have the same status in Nuer grammar - this functional asymmetry between the three length values helps to explain the existence of such a system despite its typological rarity.

\section{References}

Andersen, Torben. 1990. Vowel length in Western Nilotic languages. Acta Linguistica Hafniensia, Vol. 22, 1990, p. 5 26.

Andersen, Torben. 1999. Vowel Harmony and Vowel Alternation in Mayak (Western Nilotic). Studies in African Linguistics, Vol. 28, 1999, p. 1-29.

Dimmendaal, Gerrit. 2000. Number marking and noun categorization in Nilo-Saharan languages. Anthropological Linguistics 42.214-261.

Faust, Noam and Eitan Grossman. Forthcoming.

Gjersøe, Siri. 2016. Tone in Nuer nouns: Oblique Case and the Construct Form. Colloquium on African Languages and Linguistics, Leiden University, August 29-31.

Reid, Tatiana, and Matthew Baerman. Nuer morphophonology: vowel alternations in verbs. Colloquium on African Languages and Linguistics, Leiden University, August 29-31.

Reid, Tatiana. 2010. Aspects of phonetics, phonology and morphophonology of Thok Reel. Edinburgh: University of Edinburgh M.Sc. dissertation. Online: http://www.era.lib.ed.ac.uk/bitstream/1842/5312/1/ThokReel_Reid2010.pdf

Remijsen, Bert \& Leoma Gilley. 2008. "Why are three-level vowel length systems rare? Insights from Dinka (Luanyjang dialect)". Journal of Phonetics 36: 318-344

Storch, Anne. 2005. The Noun Morphology of Western Nilotic. Cologne: Köppe.

Vandervort, Eleanor. n.d. Nuer field notes. (Draft pedagogical grammar and scanned index cards.) Online: http://www.dlib.indiana.edu/collections/nuer/. 